\title{
Role of Different Doses of Vitamin $E$ in Protection Against Isoproterenol-Induced Myocardial Damage in Adult Male Albino Rat: A Light and Electron Microscopic Study
}

\author{
Original \\ Azza Awad AboRaya', Marwa A. A. Ibrahim ${ }^{1}$ and Habib A. Qureshi ${ }^{2}$ \\ Article \\ ${ }^{1}$ Department of Histology Faculty of Medicine, Tanta University, Egypt \\ ${ }^{2}$ Department of Biomedical Sciences, Collage of Medicine, King Faisal University, Saudi \\ Arabia
}

\begin{abstract}
Introduction: Cardiovascular diseases are one of the most common diseases in the world. It is essential to find an efficient natural protective agent against the myocardial damage.

Aim: To determine the protective role of different doses of vitamin $\mathrm{E}$ against isoproterenol-induced myocardial damage.

Material and Methods: Fifty adult male albino rats were divided into four main groups: Control group (I), vitamin E-treated group (II) equally divided into 2 subgroups; subgroup (IIa) received Vit E (50mg/kg) and subgroup (IIb) received Vit E $(100 \mathrm{mg} / \mathrm{kg})$ for one month, isoproterenol-treated group (III) received $3 \mathrm{ml}$ normal saline orally for one month and isoproterenol $(150 \mathrm{mg} / \mathrm{kg}$ ) intraperitoneally (IP) in the last two days of that month. Vitamin E and isoproterenol-treated group (IV) equally divided into two subgroups; Subgroup (IVa) received vitamin E $(50 \mathrm{mg} / \mathrm{kg}$ ) orally for one month and isoproterenol $(150 \mathrm{mg} / \mathrm{kg}$ ) IP in the last two days of that month and subgroup (IVb) received vitamin E $(100 \mathrm{mg} / \mathrm{kg})$ orally for one month and isoproterenol $(150 \mathrm{mg} / \mathrm{kg})$ IP in the last two days of that month. Heart specimens were processed for light and electron microscopic studies. Results: Rats injected by isoproterenol developed structural changes in the myocardium in the form of fragmentation of the myofibrils, vacuolated destroyed mitochondria, dilated SER, intracellular and extracellular edema and interstitial mononuclear cellular infiltration. Animals pretreated with vitamin $\mathrm{E}$ at a dose of $50 \mathrm{mg} / \mathrm{kg}$ before injection of isoproterenol revealed minimal protection as they showed myocardial damage similar to isoproterenol-treated group. While animals pretreated with vitamin $\mathrm{E}$ at a dose of $100 \mathrm{mg} / \mathrm{kg}$ before injection of isoproterenol showed minimal microscopic alterations of the myocardium with preservation of the normal structure of the cardiac myocytes.

Conclusion: Vitamin E at a high dose $(100 \mathrm{mg} / \mathrm{kg})$ has a protective role on myocardium against isoproterenol- induced myocardial damage.
\end{abstract}

Keywords: Electron microscopy, isoproterenol, myocardial damage, rat, vitamin E

Revised: 23 February 2017, Accepted: 6 July 2017

Corresponding Author: Marwa A. A. Ibrahim, MD, Department of Histology, Faculty of Medicine, Tanta University, Tanta, Egypt, Tel.0020-1099186399, E-mail: maleox68@yahoo.com, marwa.ibrahim@med.tanta.edu.eg

ISSN: 1110-0559, 2017, Vol 40. , No. 2

\section{INTRODUCTION}

Myocardial infarction (MI) is considered the leading causes of death in men and women in both developed and developing countries. In spite of basic and clinical advancements, MI remains one of the most common and lethal health problems in the modern world ${ }^{[1,2]}$. MI is characterized by an inequity of coronary blood supply and demand, which results in myocardial ischemic injury and damages the cardiomyocytes ${ }^{[3]}$. Several studies showed that during ischemic damage, oxidative stress produced by the generation of reactive oxygen species (ROS) plays a key role in the development of MI, where ischemia exceeds a serious level for a prolonged period in MI resulting in a permanent myocardial cell injury and/ or death ${ }^{[4,5]}$.

Isoproterenol (ISO) is a potent synthetic catecholamine and $\beta$-adrenergic agonist with powerful bronchodilator and cardiac stimulant actions. It is used in the management of shock, treatment and prevention of cardiac standstill, arrhythmias and treatment of bronchospasm during anesthesia ${ }^{[6]}$. It has been widely reported to produce MI when administered in large doses. Isoproterenol generates highly cytotoxic free radicals that stimulate membrane phospholipids peroxidation thus causing severe damage to the myocardial membrane in addition to many metabolic and morphologic alterations. Therefore, it is commonly used to produce MI model in rats ${ }^{[7,8]}$.

Reactive oxygen radicals play a central role in the pathophysiology of ISO-induced myocardial infarction ${ }^{[9,10]}$. Thus biological compounds with antioxidant properties could be expected to significantly contribute to the protection of myocardial cells and tissues against deleterious effects of ISO [11] Nevertheless, numerous synthetic antioxidants have 
expressed serious limitations while showing pro-oxidant, toxic or mutagenic effects, thus, raised the attention of researchers towards the naturally derived antioxidants ${ }^{[12]}$.

Previous studies considered many plants as dietary antioxidants such as sulphur-containing compounds in garlic, phytoestrogens in soy, green tea, anthocyanins in red berries, lycopene in tomatoes, grape seeds extract and most recently ancient Indian species like cardamom. Those naturally derived antioxidants are increasingly recognized as potential protective agents to reduce the risk of cardiovascular diseases ${ }^{[12,13]}$.

Vitamin E (vit E) is the predominant lipophilic antioxidant in plasma membrane and tissues. In addition to its antioxidant properties, vit $\mathrm{E}$ has been proposed to slow or inhibit the oxidative modification of LDL responsible for development and progression of atherosclerosis ${ }^{[14,15]}$. Although some studies attributed the protective effect of vit $\mathrm{E}$ administration on cardiovascular diseases to its antioxidant property acting through peroxyl radical tapping chain-breaking antioxidant action ${ }^{[16]}$. Yet researches have shown that vit E possesses a variety of cardiovascular effects includes decreasing platelet aggregation, arterial superoxide generation and increasing eNOS-mediated NO production ${ }^{[17,18]}$.

\section{AIM OF THE WORK}

Therefore, this study was designed to determine the possible protective effect of different oral doses of vitamin $\mathrm{E}$ against isoproterenol-induced myocardial infarction in adult male albino rat.

\section{MATERIAL AND METHODS}

\section{Experimental animals:}

Fifty adult male albino rats (200 -230 grams, each) were used. All animals were kept under the same hygienic conditions, housed in well ventilated animal cages and received balanced diet and given water ad libitum throughout the whole duration of experiment (1 month). The experimental protocol was approved by the local Animal Care Committee of King Faisal University. The experimental procedures were carried out in accordance with international guidelines for care and use of laboratory animals.

\section{Drugs:}

Isoproterenol (ISO) was procured from Sigma Chemical Co. (St. Louis, Mo, USA), catalogue number (I2760). It was dissolved in normal saline $(0.9 \% \mathrm{NaCl})$ and administered intraperitoneal (i.p) as a single daily dose of $150 \mathrm{mg} / \mathrm{kg}$ body weight dissolved in $2 \mathrm{ml}$ normal saline in the last two days of the experiment (on the $29^{\text {th }}$ and $30^{\text {th }}$ day) ${ }^{[19,20]}$.
Vitamin E ( $\alpha$-Tocopherol) was procured from Sigma Chemical Co. (St. Louis, Mo, USA), catalogue number (258024). It was administered at a dose of 50 or $100 \mathrm{mg} /$ $\mathrm{kg}$ body weight ${ }^{[21]}$. The calculated dose was suspended in $3 \mathrm{ml}$ normal saline and given as a single daily dose orally for one month by using stainless steel feeding needles.

\section{Experimental design:}

Animals were divided into four main groups, Group I (Control) $(\mathrm{n}=10)$, animals were equally divided into two subgroups; Subgroup (Ia), animals were kept without any treatment, and subgroup (Ib), each animal received $3 \mathrm{ml}$ normal saline orally once daily for one month by the feeding needle and was given 2 $\mathrm{ml}$ normal saline IP once daily in the last 2 days of that month (on the 29th and 30th day).

Group II (Vitamin E-treated): $(\mathrm{n}=10)$ animals were equally divided into two subgroups; Subgroup (IIa), each animal received vitamin E $(50 \mathrm{mg} / \mathrm{kg}$ b.wt) suspended in $3 \mathrm{ml}$ normal saline orally once daily for one month and was given $2 \mathrm{ml}$ normal saline IP once daily in the last 2 days of that month (on the $29^{\text {th }}$ and $30^{\text {th }}$ day). Subgroup (IIb), each animal received vitamin E (100mg/kg b. wt.) suspended in $3 \mathrm{ml}$ normal saline orally once daily for one month and was given $2 \mathrm{ml}$ normal saline IP once daily in the last 2 days of that month (on the $29^{\text {th }}$ and $30^{\text {th }}$ days).

Group III (Isoproterenol-treated): $(\mathrm{n}=10)$ each animal received $3 \mathrm{ml}$ normal saline orally once daily for one month and was given ISO (150 mg/Kg b.wt) IP dissolved in $2 \mathrm{ml}$ normal saline once daily in the last 2 days of that month (on the $29^{\text {th }}$ and $30^{\text {th }}$ day).

Group IV (Vitamin E and Isoproterenol-treated): $(n=20)$, equally divided into two subgroups: Subgroup (IVa): $(\mathrm{n}=10)$ each animal received Vit $\mathrm{E}(50 \mathrm{mg} / \mathrm{Kg}$ b.wt) suspended in $3 \mathrm{ml}$ normal saline orally once daily for one month and was given ISO $(150 \mathrm{~m} / \mathrm{Kg}$ b.wt) dissolved in $2 \mathrm{ml}$ normal saline IP in the last 2 days of that month (on the $29^{\text {th }}$ and $30^{\text {th }}$ days). Subgroup (IVb): $(\mathrm{n}=10)$ each animal received Vit $\mathrm{E}(100 \mathrm{mg} / \mathrm{Kg}$ b.wt $)$ suspended in $3 \mathrm{ml}$ normal saline orally once daily for one month and was given ISO (150mg / Kg b.wt) dissolved in $2 \mathrm{ml}$ normal saline IP once daily in the last 2 days of that month (on the $29^{\text {th }}$ and $30^{\text {th }}$ day).

At the end of the experiment, the animals were not given any drug for 24 hours after the last injection of isoproterenol then anesthesia was induced by thiopental sodium $(40 \mathrm{mg} / \mathrm{kg})$ IP $^{[22]}$. The heart was rapidly dissected out and washed immediately with saline, and specimens from the left ventricle were prepared for light and electron microscopic examinations. 


\section{For light microscopic study:}

Pieces of the left ventricle of the heart were fixed in $10 \%$ formol saline for $24 \mathrm{hrs}$. The fixative was removed by washing through running tap water. After dehydration through a graded series of alcohol, specimens were processed and embedded in paraffin wax. Sections were cut into $5 \mu \mathrm{m}$ thickness and stained with hematoxylin and eosin (H\&E) ${ }^{[23]}$. The sections were observed under light microscope (Olympus BX51, Tokyo, Japan) for histological changes and the photographs were taken by digital camera (Olympus DP50, Tokyo, Japan) "12 mega pixel" at the Histology department, Faculty of Medicine, Tanta University, Egypt.

\section{For electron microscopic study:}

Small pieces of the left ventricle of the heart (12- $\mathrm{mm}$ ) were taken and immediately fixed in $2.5 \%$ glutaraldehyde in $0.1 \mathrm{M}$ cacodylate buffer $(\mathrm{PH}, 7.2)$ at a temperature of $4^{\circ} \mathrm{C}$ for $1 \mathrm{hr}$. and were washed in cacodylate buffer. These were post fixed in $1 \%$ osmium tetraoxide in cacodylate buffer for 90 minutes at room temperature, dehydrated in acetone, and embedded in Epoxy araldite mixture. Ultrathin sections were obtained in a Leica EMUC6 ultramicrotome, placed on copper grids, and stained with uranyl acetate and lead citrate ${ }^{[24]}$ for detailed examination which was carried out using a JEM 1011 (JOEL, Tokyo, Japan) electron microscope at $80 \mathrm{KV}$ at the department of Biomedical sciences, Faculty of Medicine, King Faisal University, Kingdom of Saudi Arabia.

\section{RESULTS}

\section{Light microscopic results:}

Haematoxylin and eosin (H\&E)-stained myocardium sections from both control subgroups; Ia and Ib showed similar normal histological structure. The sections revealed regular, adjacent myocardial fibers and muscle bundles. The longitudinal muscle fibers were branched, anastomosed and continuous with adjacent fibers (Fig. 1a). The transverse muscle fibers appeared rounded with minimal variations in their diameters and surrounded with delicate connective tissues "endomysium" (Fig. 1b). Each cardiac muscle fiber showed acidophilic cytoplasm and one or two pale oval or rounded central nuclei (Figs. 1a and 1b). In the longitudinal sections, muscle fibers were interwoven with myofibrils arranged parallel to the longitudinal axis of the muscle fibers' cross striations in the cytoplasm of the myocytes could be observed (Fig. 2a). The transverse sections showed rounded muscle fibers with homogenous granular acidophilic cytoplasm and surrounded by delicate connective tissues with fibroblasts (Fig. 2b).
H\&E-stained myocardium sections from both group II (Vitamin E-treated) subgroups; IIa and IIb showed similar normal histological architecture as control group I.

H\&E-stained myocardium sections from group III (Isoproterenol-treated) showed marked histological changes in the cardiac muscle fibers. The myocardium revealed wide separation of cardiac muscle fibers and dilatation of intercellular spaces in between longitudinal and transverse myocytes. Focal extensive interstitial mononuclear cellular infiltration and dilated blood capillaries with hemorrhage and extravasated blood cells in between myocardial fibers were seen (Figs. 3a and $3 b$ ). Some myocardial fibers were severely affected; they showed intensely eosinophilic homogenous cytoplasm. Focal areas of fragmentation and cytolysis of myofibers with loss of the cross striations in their cytoplasm were observed (Figs. $4 \mathrm{a}$ and $4 \mathrm{~b}$ ).

H\&E-stained myocardium sections from subgroup IVa $(50 \mathrm{mg} / \mathrm{kg}$ vitamin E pretreated animals) revealed areas of fragmented myocytes in addition to focal areas of vacuolated sarcoplasm, interstitial and intercellular mononuclear cellular infiltration in between myocytes in addition to dilated congested blood vessels with intercellular and interstitial hemorrhage (Fig. 5). Focal areas of destructed and fragmented myocytes with dark eosinophilic cytoplasm were observed (Fig. 6).

H\&E-stained myocardium sections of subgroup $\mathrm{IVb}(100 \mathrm{mg} / \mathrm{kg}$ vitamin E pretreated animals) showed evident preservation of the normal histological structure of cardiac muscle fibers. Longitudinal muscle fibers appeared branched and anastomosed with acidophilic cytoplasm and centrally pale oval nuclei with prominent nucleoli. Prominent appearance of the cross striations of myofibrils in the cytoplasm of muscle fibers were also seen (Figs. 7 and 8a). However, focal areas of dilated spaces in between myocardial fibers and mild dilated congested blood capillaries along with focal areas of mild interstitial mononuclear cellular infiltration were observed (Fig. 7). The transverse sections of myocardial fibers showed homogenous acidophilic cytoplasm with central pale rounded nuclei and surrounded by delicate connective tissues (Fig. 8b).

\section{Electron microscopic results:}

EM examination of both control subgroups; Ia and Ib showed similar normal histological structure. In longitudinal sections, the sarcoplasm showed myofilments with the characteristic arrangement in the sarcomeres, rows of variable sized mitochondria and profiles of sarcoplasmic reticulum in between myofibrils (Fig. 9). In cross sections, the sarcoplasm of myocytes appeared to contain myofibrils interrupted by mitochondria (Fig. 10). 
The nuclei were oval and centrally located with extended chromatin (Figs. 9 and 10). Higher magnification revealed the mitochondria arranged in rows in between myofibrils, they appeared spherical with abundant closely packed tubular cristae. The regular transverse striations of myofibrils were formed of dark (A) bands with their central pale $(\mathrm{H})$ zones and light $(\mathrm{I})$ bands bisected by (Z) lines, abundant amount of glycogen granules were also observed (Fig. 11). In between myocytes, intact intercalated discs with step-like pattern formed of desmosomes in their transverse parts and gap junctions in their longitudinal parts were observed (Fig. 12).

EM examination of myocardium ultrathin sections from both group II (Vitamin E-treated) subgroups; IIa and IIb showed similar normal histological architecture as control group I.

EM examination of the cardiac myocytes from group III (Isoproterenol-treated) revealed fragmentation and lysis of myofilaments of myocytes sarcoplasm with focal loss of the sarcomeres normal arrangement. Variable shape, size and irregular arrangement of mitochondria with dense homogenous mitochondrial matrix, in addition to dilatation of sarcoplasmic reticulum with accumulation of intracellular and interstitial fluid were observed. Interstitial macrophages with secondary lysosomes were also observed (Figs. 13 and 14). Some nuclei appeared oval with irregular outline of their nuclear membrane, extended chromatin and prominent nucleoli (Fig. 13). On higher magnification, some mitochondria appeared swollen and vacuolated with partial loss of their cristae (Fig. 15). Intact intercalated discs in between myocytes with high irregularity of their pattern were observed (Fig. 16). Few glycogen granules could be observed (Figs. 15, 16).

EM examination of the cardiac myocytes from subgroup IVa (50 $\mathrm{mg} / \mathrm{kg}$ vitamin E pretreated animals) revealed similar cardiac myocytes findings to group III. The sarcoplasm of myocytes showed focal areas of lysis and fragmentation of myofilaments with focal loss of arrangement of sarcomeres pattern. Mitochondria were arranged in irregular rows in between myofibrils with variable shape and size with dense homogenous matrix together with dilatation of sarcoplasmic reticulum (Figs. 17 and 18). Interstitial cellular infiltration as fibroblasts was observed (Fig. 17). Intact intercalated discs in between myocytes with highly irregular pattern and abundant amount of glycogen granules were observed (Fig. 19).

EM examination of the cardiac myocytes from subgroup IVb (100 mg/kg vitamin E pretreated animals) showed evident preservation of the cardiac myocytes. The sarcoplasm of myocytes revealed intact myofilaments with the normal arrangement of sarcomeres pattern. The mitochondria appeared of variable sizes with abundant packed cristae arranged in rows in between myofibrils and were accumulated in the perinuclear region. The nuclei appeared oval with extended chromatin and prominent nucleoli (Figs. 20 and 21). Focal areas of mild dilatation of sarcoplasmic reticulum and intercellular infiltration "fibroblasts" were observed (Fig. 21). The intercalated discs in between myocytes appeared intact with step-like appearance together with abundant amount of glycogen granules (Fig. 22).

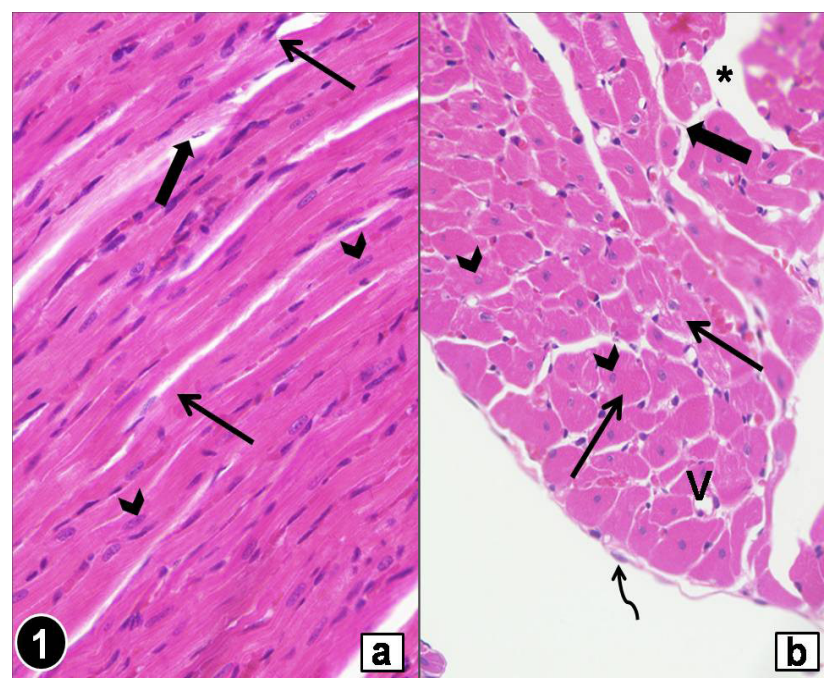

Fig. 1: Photomicrographs of sections of rat myocardium from control group I showing (a) branching and anastomosing longitudinal muscle fibers (thin arrows) with central oval nuclei (arrowheads). Notice the connective tissue (thick arrow) in between muscle fibers, (b) transverse muscle fibers (thin arrows) with central rounded nuclei (arrow heads), blood capillaries (v) and delicate connective tissues (thick arrow) in between cardiac myocytes. The endocardium (wavy arrow) with simple squamous epithelial cells is seen. Notice the space between muscle bundles (asterisk).

(H\&E X 400).

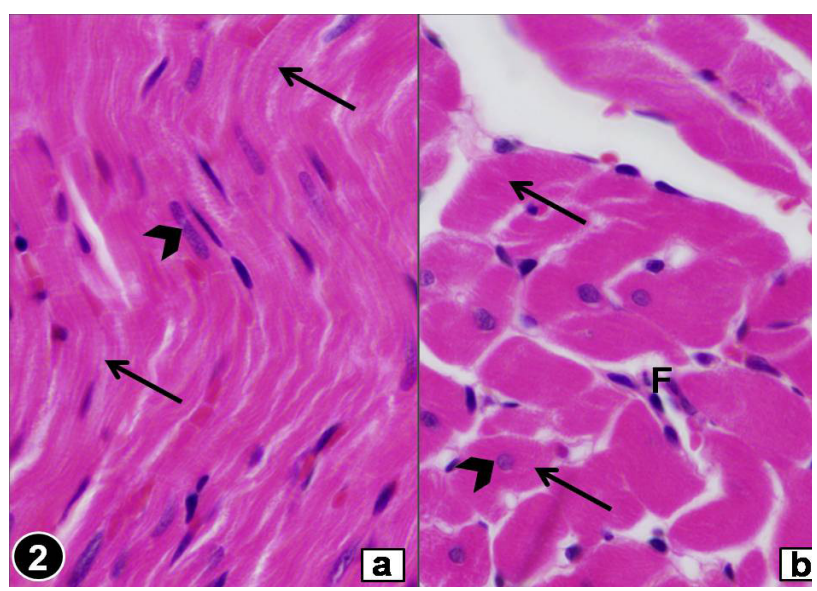

Fig. 2: . Photomicrographs of sections of rat myocardium from control group I showing (a) interwoven longitudinal cardiac muscle fibers with myofibrils cross striations (thin arrows) in the cytoplasm and central oval nuclei (arrow head). (b) transverse muscle fibers with acidophilic cytoplasm (thin arrows) and pale central rounded nuclei (arrow head). Interstitial fibroblasts (F) are seen.

(H\&E X 1000) 


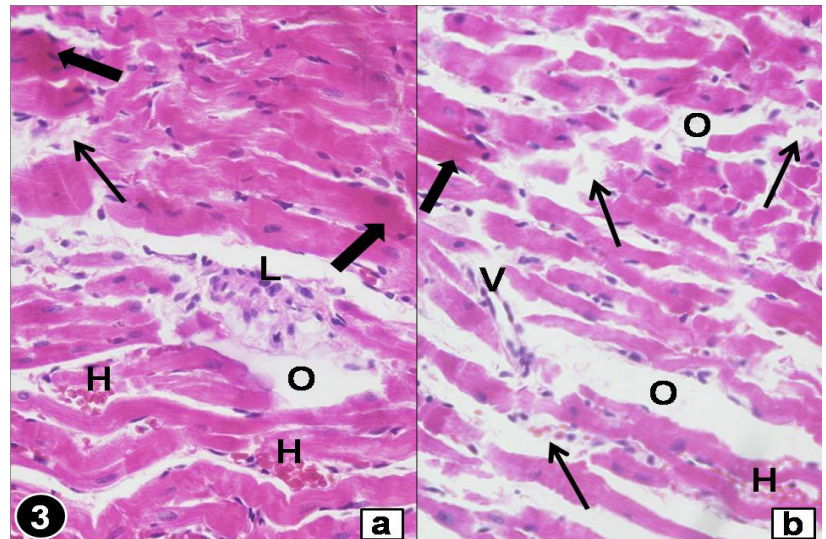

Fig. 3: Photomicrographs of sections of rat myocardium from group III (isoproterenol-treated group) showing (a) interstitial mononuclear cellular infiltration (L). Some myocytes with deeply eosinophilic cytoplasm (thick arrows) and areas of hemorrhage and extravasated blood $(\mathrm{H})$ are observed. (b) dilated spaces between longitudinal and transverse cardiac muscle fibers $(\mathrm{O})$. Focal areas of destruction and cytolysis of myocytes (thin arrows) are observed. Numerous myocytes with deeply eosinophilic cytoplasm (thick arrow) and dilated blood capillaries (V) are seen. Notice area of hemorrhage and extravasated blood $(\mathrm{H})$.

(H\&E X 400).

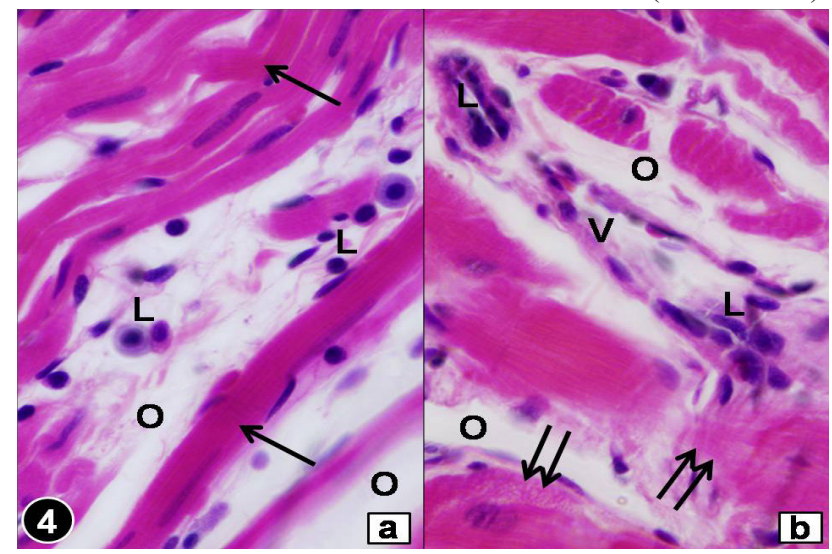

Fig. 4: Photomicrographs of sections of rat myocardium from group III (isoproterenol-treated group) showing (a) widely separated cardiac muscle fibers $(\mathrm{O})$ and necrotic myocytes with deeply eosinophilic cytoplasm (arrows). Notice intercellular mononuclear cellular infiltration (L). (b) focal areas of fragmented myofibers with focal loss of cross striations (double arrows) Notice dilated blood capillary (V) with interstitial mononuclear cellular infiltration $(\mathrm{L})$.

(H\&E X 1000)

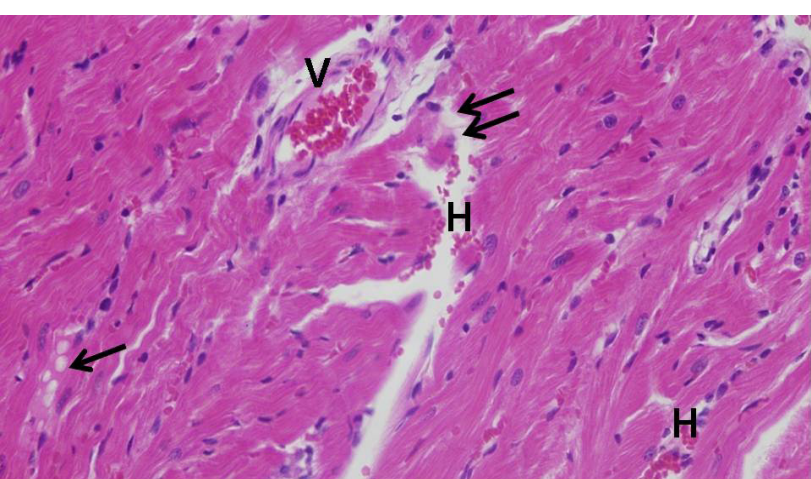

Fig. 5: A photomicrograph of a section of rat myocardium from subgroup IVa (Vit E $50 \mathrm{mg} / \mathrm{Kg}$ pretreated group) showing focal areas of fragmented (double arrows), and vacuolated myocytes (thin arrow). Notice interstitial and intercellular mononuclear cellular infiltration $(\mathrm{L})$, interstitial hemorrhage $(\mathrm{H})$ and dilated congested blood vessel (V).

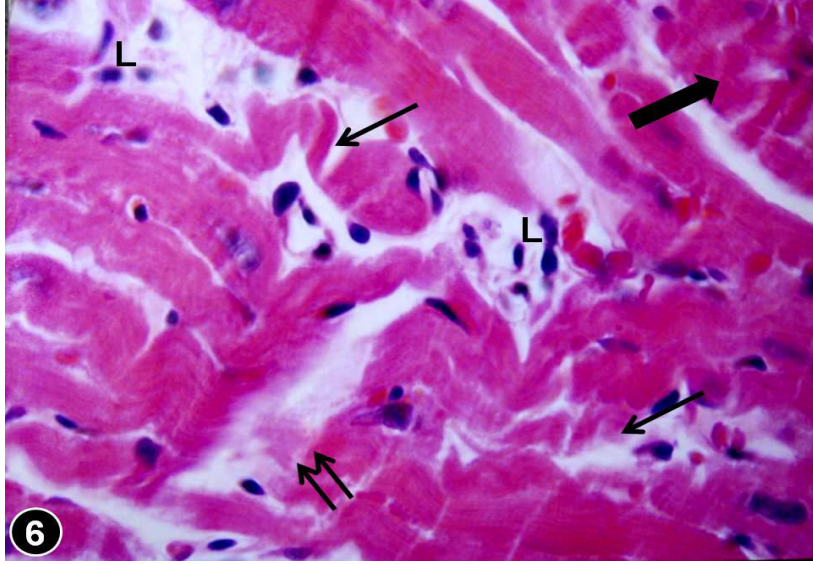

Fig. 6: A photomicrograph of a section of rat myocardium from subgroup IVa (Vit E $50 \mathrm{mg} / \mathrm{Kg}$ pretreated group) showing irregular longitudinal cardiac muscle fibers (thin arrows) with areas of fragmentation and lysis of myocytes (double arrows), focal myocytes with deeply eosinophilic cytoplasm (thick arrow) and interstitial mononuclear cellular infiltration (L).

(H\&E X 1000)

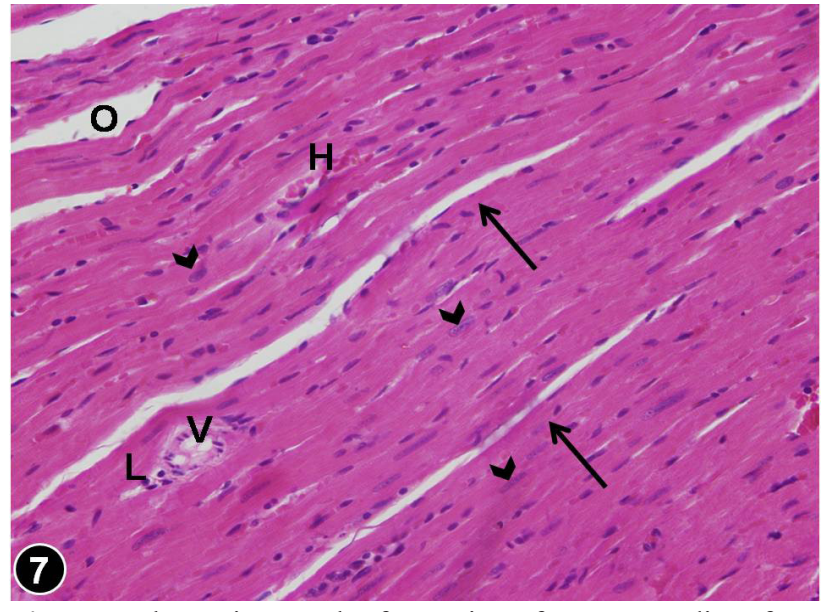

Fig. 7: A photomicrograph of a section of rat myocardium from subgroup IVb (Vit E $100 \mathrm{mg} / \mathrm{Kg}$ pretreated group) showing closely adjacent and regular longitudinal cardiac muscle fibers (thin arrows) with central oval nuclei (arrow heads). Notice focal spaces between myocytes $(\mathrm{O})$, intercellular hemorrhage $(\mathrm{H})$ and blood vessel (V) surrounded by mononuclear cellular infiltration (L).

(H\&E X 400).

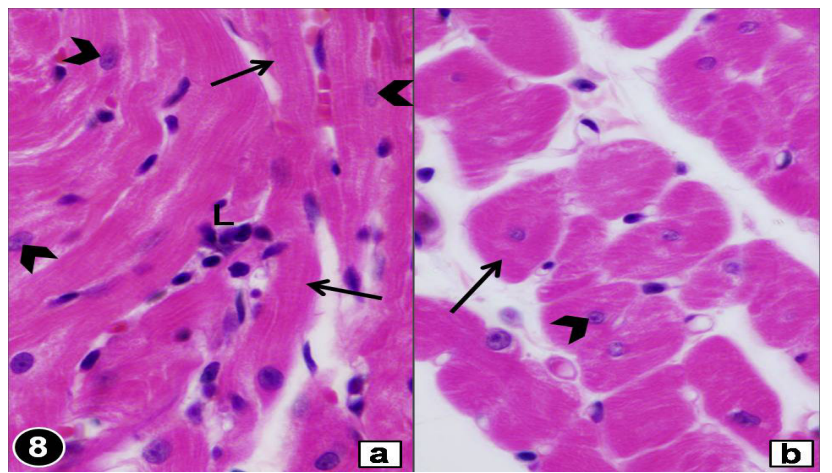

Fig. 8: Photomicrographs of sections of rat myocardium from subgroup IVb (Vit E $100 \mathrm{mg} / \mathrm{Kg}$ pretreated group) showing (a) longitudinal branched cardiac muscle fibers with prominent cross striations (thin arrows) of myofibrils and central oval nuclei (arrowheads). Notice area of mild intercellular mononuclear cellular infiltration (L). (b) transverse cardiac muscle fibers with acidophilic cytoplasm (thin arrow) and central pale rounded nuclei (arrowhead) with prominent nucleoli.

(H\&E X 1000) 


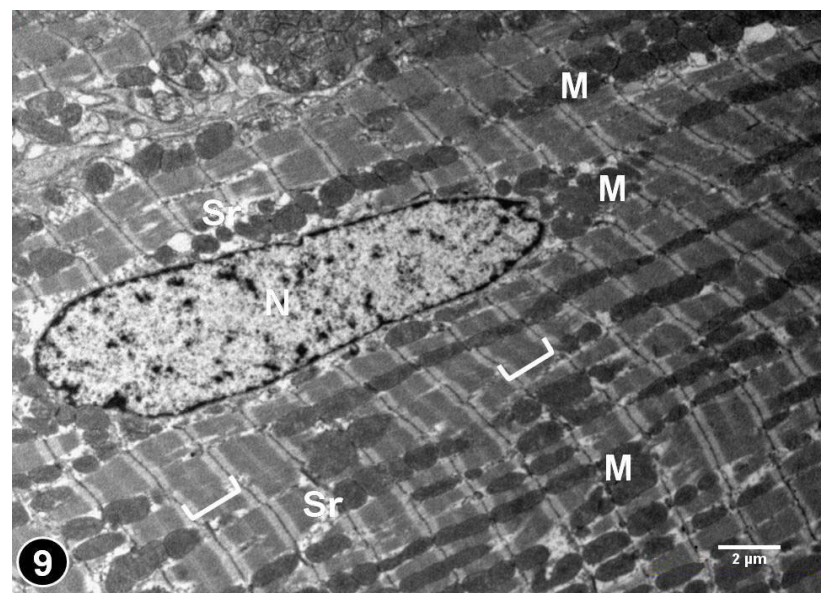

Fig. 9: An electron micrograph of cardiac myocyte from control group I showing regular myofilaments arranged in sarcomeres (brackets), variable sized mitochondria (M) arranged in rows in between myofibrils and profiles of sarcoplasmic reticulum $(\mathrm{Sr})$ in between myofibrls. Notice central oval nucleus with extended chromatin $(\mathrm{N})$ (TEM X 5000).

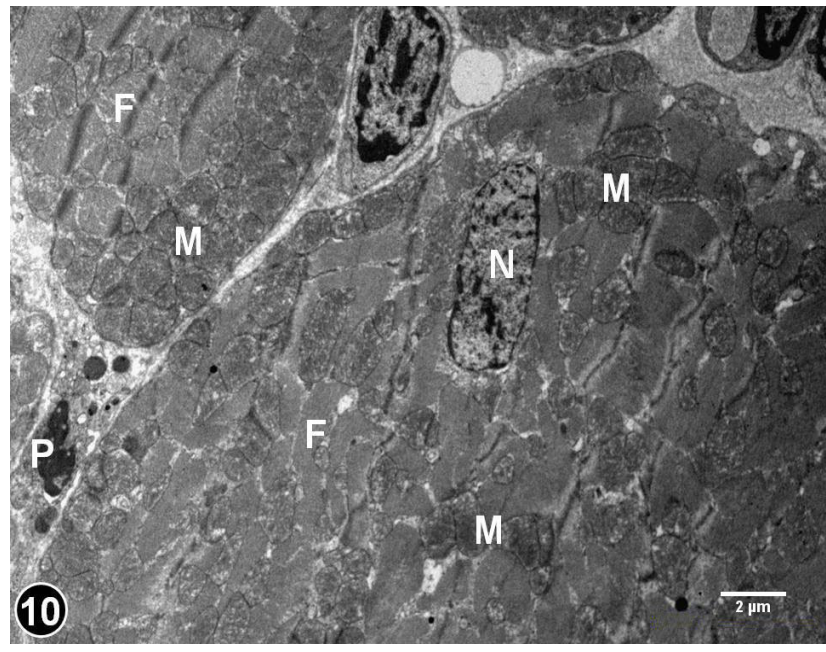

Fig. 10: An electron micrograph of two adjacent cardiac myocytes from control group I showing sarcoplasm with myofibrils (F), variable sized mitochondria $(\mathrm{M})$ and a central oval nucleus $(\mathrm{N})$ with extended chromatin. Notice an interstitial macrophage $(\mathrm{P})$.

(TEM X 5000)

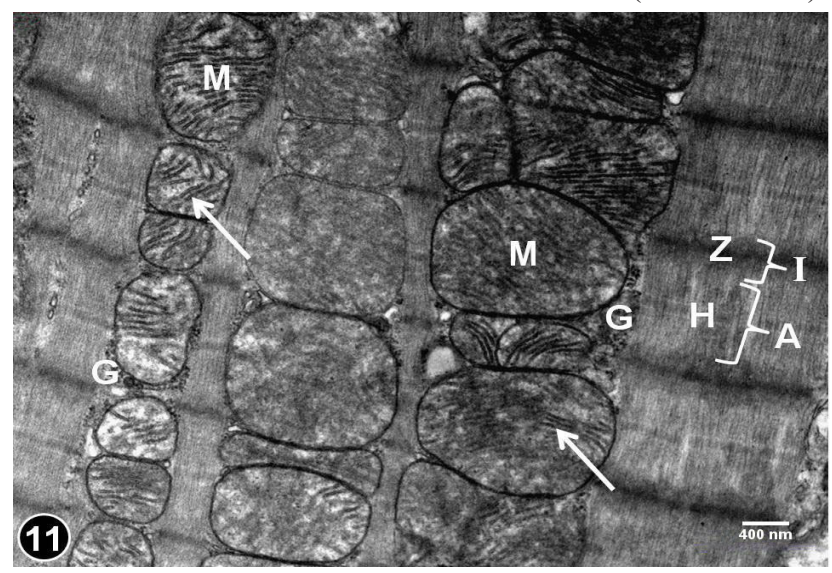

Fig. 11: An electron micrograph of sarcoplasm of cardiac myocyte from control group I showing regular rows of mitochondria (M) with their tubular packed prominent cristae (arrows) and regular transverse striations of myofibrils formed of dark (A) and light (I) bands bisected by $(\mathrm{Z})$ lines. The center of each (A) band has a pale $(\mathrm{H})$ zone. Notice the glycogen granules in between myofibrils $(\mathrm{G})$ (TEM X 20000).

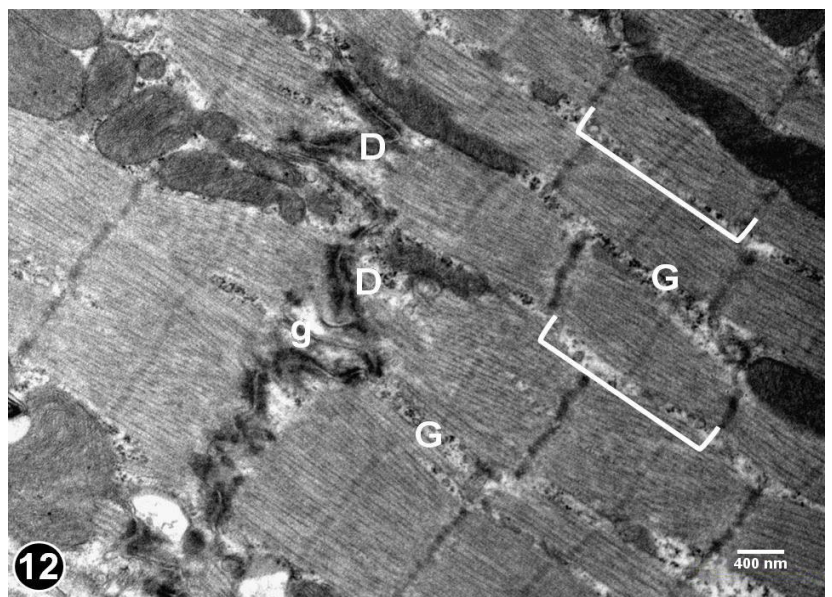

Fig 12: An electron micrograph of cardiac myocytes from control group I showing an intact intercalated disc in between myocytes with a step-like pattern formed of desmosomes (D) and gap junctions (g). Notice regular myofilaments arranged in sarcomeres (brackets) and abundant glycogen granules $(\mathrm{G})$.

(TEM X 20000)

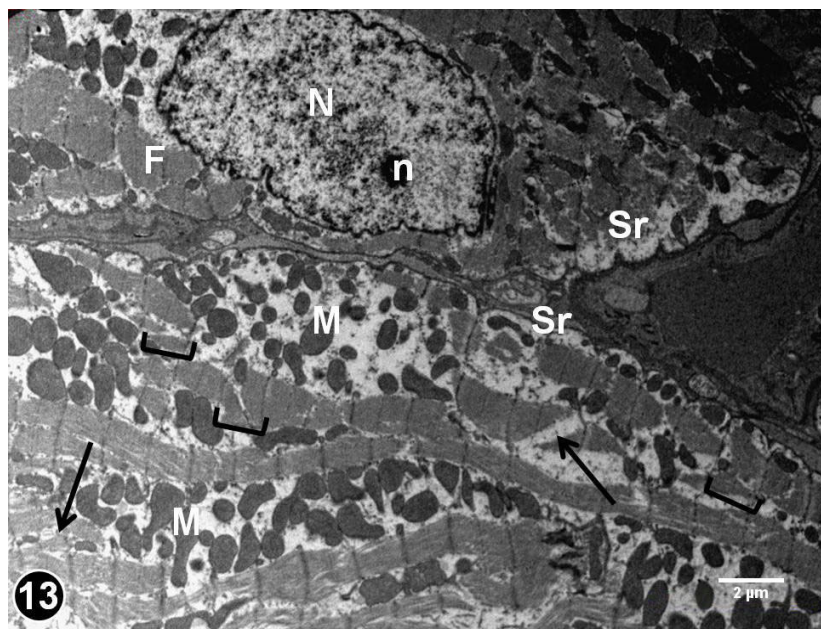

Fig. 13: An electron micrograph of two cardiac myocytes from group III showing fragmentation (arrows) and irregular arrangement of myofilaments with partial loss of the normal pattern of sarcomeres (brackets) and loss of regular arrangement of myofibrils (F). A nucleus (N) with irregular outline of nuclear membrane and prominent dark nucleolus (n) is observed. Notice dilated sarcoplasmic reticulum $(\mathrm{Sr})$ and dense mitochondria $(\mathrm{M})$ with irregular shapes and arrangement.

(TEM X 5000)

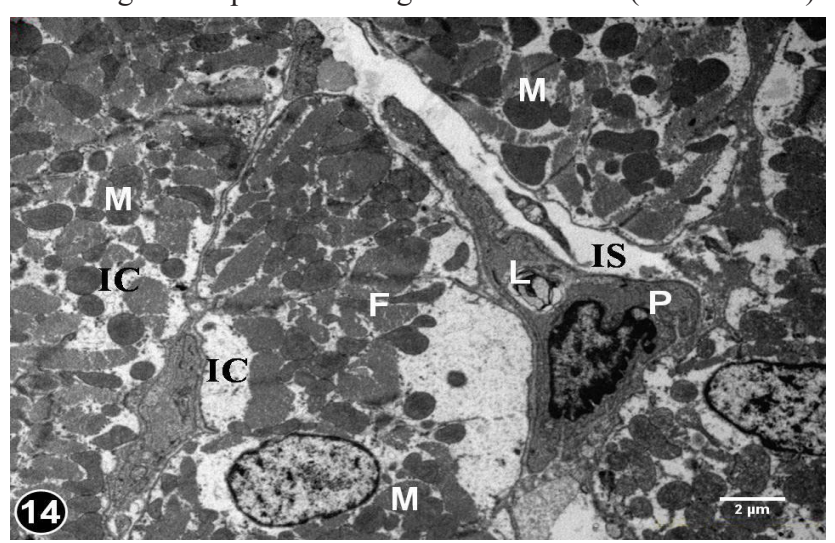

Fig. 14: An electron micrograph of cardiac myocytes from group III showing accumulation of the intracellular (IC) and interstitia (IS) fluid and loss of regular arrangement of myofibrils (F) and mitochondria $(\mathrm{M})$. Notice an interstitial macrophage $(\mathrm{P})$ with secondary lysosome in its cytoplasm (L). $\quad$ (TEM X 5000). 


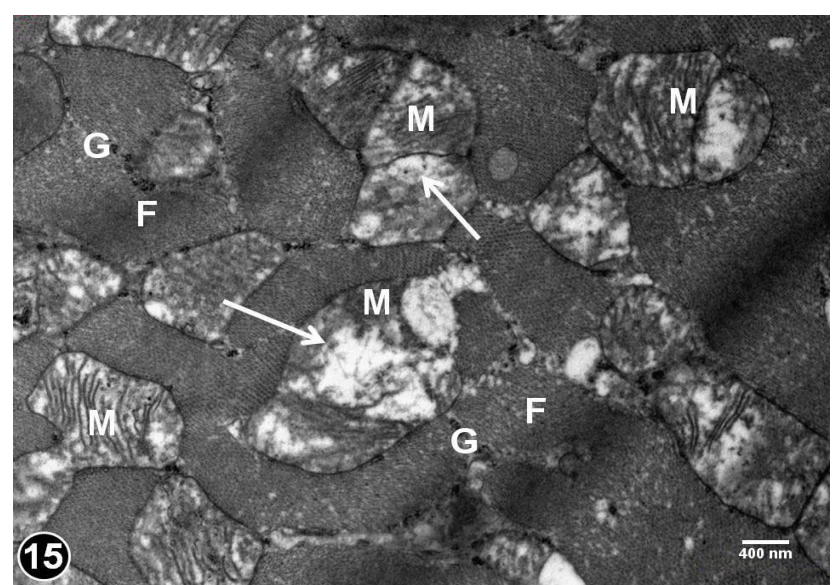

Fig. 15: An electron micrograph of cardiac myocyte from group III showing irregular fragments of myofibrils $(\mathrm{F})$ and swollen vacuolated mitochondria $(\mathrm{M})$ with partial loss of their cristae (arrows). Notice few glycogen granules $(\mathrm{G})$.

(TEM X 20000).

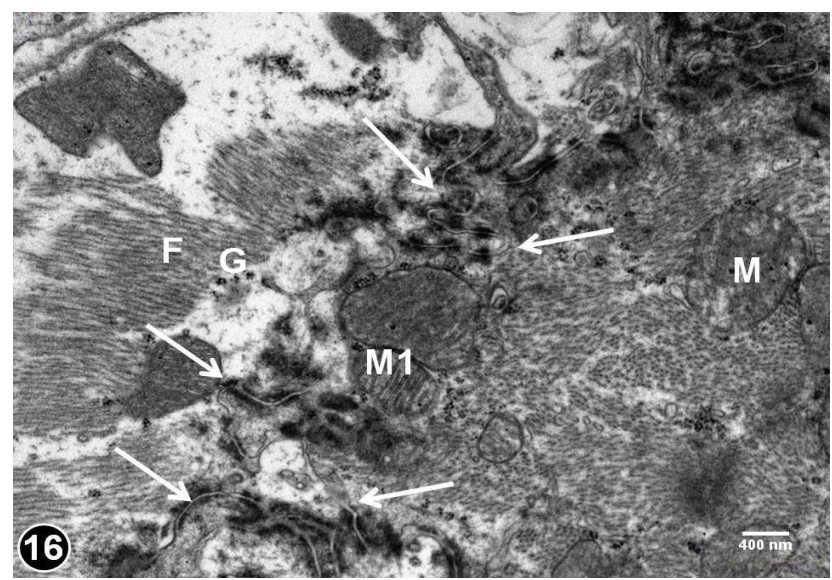

Fig. 16: An electron micrograph of cardiac myocytes from group III showing intact intercalated disc in between myocytes (arrows) with highly irregular pattern of sarcolemma of the disc. Notice fragments of myofilaments (F), destructed mitochondria (M) and some mitochondria with prominent cristae(M1). Few glycogen granules $(\mathrm{G})$ are observed (TEM X 20000).

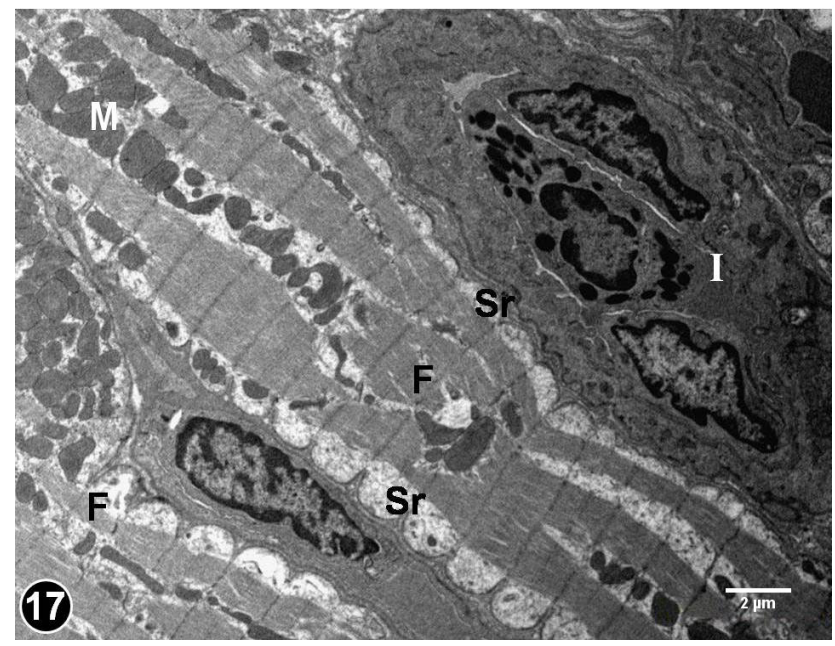

Fig. 17: An electron micrograph of cardiac myocytes from subgroup IVa (Vit E $50 \mathrm{mg} / \mathrm{Kg}$ pretreated group) showing focal area of lysis of myofibrils (F), variable shapes and sizes of mitochondria (M) in between myofibrils and dilated sarcoplasmic reticulum (Sr). Notice interstitial cellular infiltration (I).

(TEM X 5000).

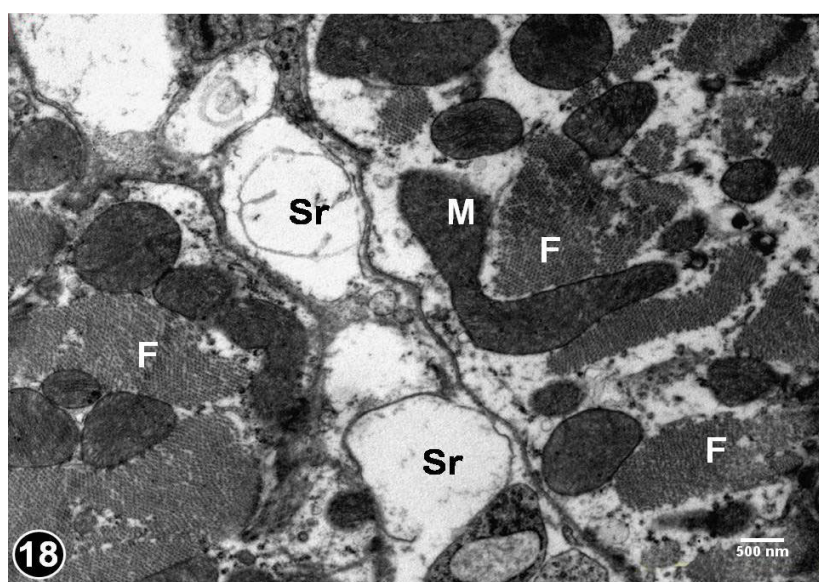

Fig. 18: An electron micrograph of cardiac myocytes from subgroup IVa (Vit E $50 \mathrm{mg} / \mathrm{Kg}$ pretreated group) showing fragments of myofibrils (F), dilated sarcoplasmic reticulum $(\mathrm{Sr})$ and variable shaped and sized mitochondria $(\mathrm{M})$ with dense matrix and ill-defined cristae.

(TEM X 15000)

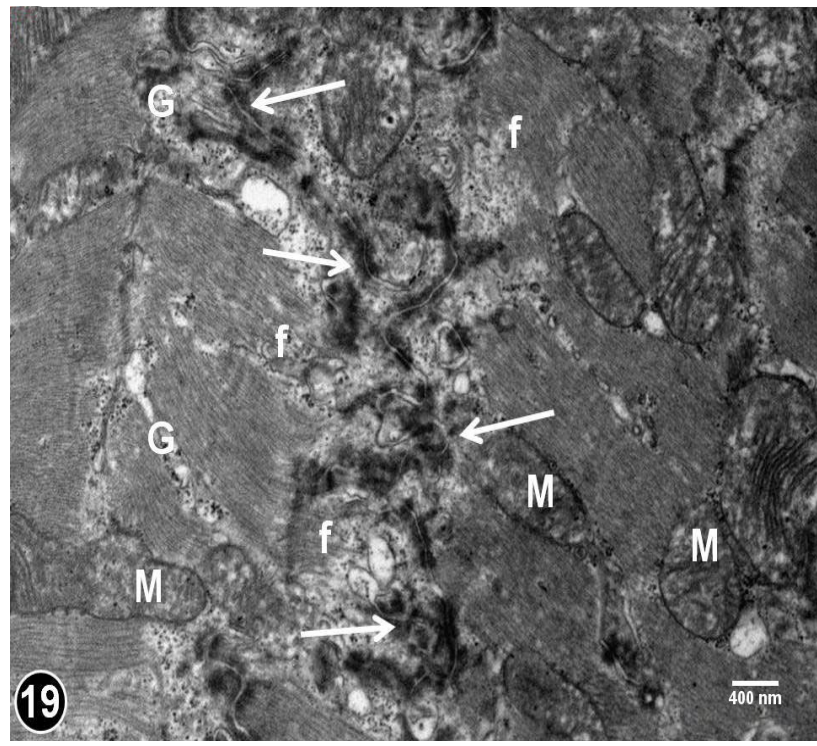

Fig. 19: An electron micrograph of cardiac myocytes from subgroup IVa (Vit E $50 \mathrm{mg} / \mathrm{Kg}$ pretreated group), showing highly irregular pattern of intact intercalated disc in between myocytes (arrows) surrounded by myofilaments (f). Notice mitochondria (M) with partial loss of their cristae and numerous glycogen granules $(\mathrm{G})$.

(TEM X 20000)

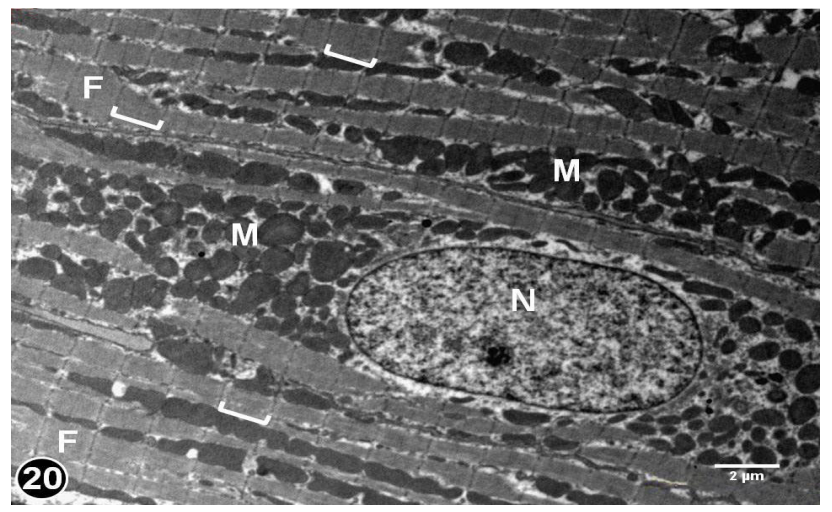

Fig. 20: An electron micrograph of cardiac myocyte from subgroup IVb (Vit E $100 \mathrm{mg} / \mathrm{Kg}$ pretreated group) showing myofibrils (F) with regular arrangement of myofilaments in the sarcomeres (brackets), regular rows of mitochondria $(\mathrm{M})$ in between the myofibrils and around the central oval nucleus with extended chromatin $(\mathrm{N})$ and prominent nucleolus. (TEM X 5000) 


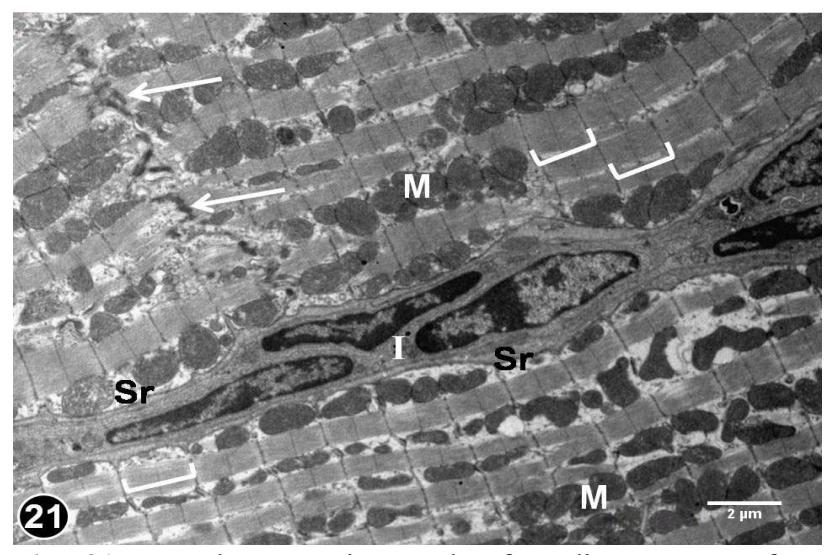

Fig. 21: An electron micrograph of cardiac myocyte from subgroup IVb (Vit E 100mg/Kg pretreated group) showing regular arrangement of myofilaments in sarcomeres (brackets), regular rows of mitochondria $(\mathrm{M})$ between myofibrils and mild dilatation of sarcoplasmic reticulum (Se). Notice intact intercalated disc with step-like pattern (arrows) and interstitial cellular infiltration (I) with fibroblasts. (TEM X 6000).

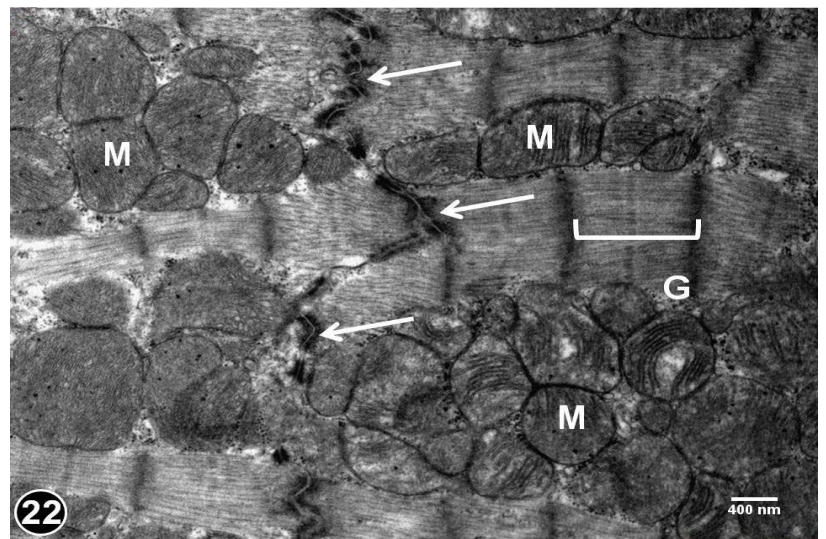

Fig. 22: An electron micrograph of cardiac myocytes from subgroup IVb (Vit E $100 \mathrm{mg} / \mathrm{Kg}$ pretreated group) showing intact intercalated disc with its step-like pattern (arrows), regular myofilaments arranged in sarcomeres (brackets) and rows of mitochondria (M) with their tubular cristae in between myofibrils. Notice abundant glycogen granules (G).

(TEM X 20000).

\section{DISCUSSION}

Myocardial infarction (MI) describes the acute condition of necrosis of the myocardium occurring as a result of imbalance between coronary blood supply and myocardial demand ${ }^{[25]}$

Isoproterenol (ISO)-induced MI commonly serves as a standardized model to investigate cardiac pathophysiology and subsequently the beneficial effects of different cardioprotective agents. ISO, when administered in large dose mimics the cardiac lesions present in $\mathrm{MI}$ in humans ${ }^{[26]}$. ISO mainly causes imbalance between cardiomyocytes oxygen supply and demand through increasing the chronotropism and inotropism essential to maintain myocardial function, in addition to increasing the calcium overload in the myocardium ${ }^{[27]}$.

In the present study, rats that received ISO showed extensive massive interstitial edema and accumulation of intercellular fluid. Alike Upaganlawar et al. ${ }^{[28]}$, proposed that the increase of the heart weight upon administration of ISO might be due the increased water content and oedematous intramuscular spaces. Asdaq et al. ${ }^{[29]}$ added that ISOinduced alterations of the membrane permeability might have brought loss of myocardial membrane function which could be another cause of the interstitial edema in experimental rats.

In the current work, light microscopy of the ISOtreated group revealed that cardiac myocytes exhibited intensely eosinophilic homogenous cytoplasm indicating coagulative myonecrosis with loss of striations and focal areas of fragmented myofibers with lysis of myofilaments. In addition to intercellular and interstitial inflammatory cellular infiltration with endothelial damage associated with hemorrhage and extravasation of blood cells in between the myocytes. These histopathological changes are in agreement with previous researchers confirming the success of the current MI model ${ }^{[8,12,26,30]}$. These changes are most probably consequential to the increase in the radical oxygen species (ROS) such as superoxide anion and hydroxyl radicals in ischemic tissues, thus resulting in oxidative damage to membrane lipids, proteins, carbohydrates and DNA ${ }^{[31]}$. The endogenous antioxidant enzyme systems are the first line of cellular defense against oxidative stress and inhibit the formation of several ROS. Following the administration of ISO, a serious down-regulation in the activities of endogenous antioxidant systems of the heart occurs, leading to the gradual loss of prooxidant/antioxidant balance with induced accumulation of ROS in cardiomyocytes that manifested as oxidative damage ${ }^{[32]}$.

Additionally, some other mechanisms were proposed to explain the isoproterenol-induced damage to cardiac myocytes include hypoxia due to inequity between myocardial activity and coronary output, depletion of energy reserve, calcium overload and free radicals production resulting from oxidative metabolism of catecholamine ${ }^{[33,34]}$

Moreover, biochemical studies of Sathish et al. ${ }^{[35]}$ confirmed that administration of ISO increases the level of both serum and myocardial lipids, causes accumulation of lipid peroxides and increases the level of low density lipoprotein (LDL) cholesterol in the blood leading to coronary heart disease. Besides, ISO alters the fragility of lysosomal membrane and increases lysosomal hydrolase activities, which might be responsible for tissue damage and infracted heart ${ }^{[36]}$. Nevertheless, inflammation was strongly suggested as a key process in mediating myocardial tissue damage after an ischemic event, where ISO was shown to increase the serum levels of c-reactive protein (CRP) and the pro-inflammatory cytokine; tumor necrosis factor-alpha $(\mathrm{TNF}-\alpha)^{[37]}$.

Ultrastructurally, sarcoplasms of ISO-treated myocytes revealed swollen, dilated and vacuolated mitochondria with disruption of their cristae and irregular distribution. Moreover, dilated sarcoplasmic reticulum and vacuolated sarcoplasm with accumulated fluid were clearly detected. These results coincided with previous studies ${ }^{[12,38,39]}$. 
Mitochondria are the main source of energy responsible for sustaining cellular metabolism and integrity. The hypoxia occurring during MI impairs energy production by mitochondria ${ }^{[40]}$. Moreover, pronounced enhancement of lipid peroxidation occurs in the mitochondria during MI. The heart mitochondrial enzymes are located in the outer membrane of the mitochondria and are seriously affected by oxidative stress caused by ISO administration ${ }^{[41]}$.

Additionally, glycogen granules were apparently fewer in ISO-treated group, which coincided with the findings of Fewell and Zhang ${ }^{[42]}$, who provided evidence that heart glycogen significantly decreased upon ISO treatment. Glycogen depletion was discussed to be one of the important underlying mechanisms of ISO-induced cardiac damage ${ }^{[43]}$

Taken together, it could be implied from the proposed mechanism of ISO-induced MI that therapeutic intervention with antioxidants may prove beneficial in preventing these deleterious changes. Farvin et al. ${ }^{[44]}$ suggested that myocardial damage might be prevented through supplementation with vitamin $\mathrm{E}$ for its strong antioxidant capacity previously encountered in several ischemic-reperfusion studies.

In the current work, animal group pretreated with 50 $\mathrm{mg} / \mathrm{kg}$ of vitamin E before ISO showed no apparent protection of cardiac muscle fibers, all necrotic changes were observed together with lysis of myofibrils and loss of the characteristic sarcomeres pattern. The mitochondria were destroyed and vacuolated with loss of their cristae. This finding coincided with previous studies ${ }^{[21]}$.

On the other hand, rats pretreated with $100 \mathrm{mg} / \mathrm{kg}$ of vitamin $\mathrm{E}$ before ISO revealed an evident protective effect on the myocardium, where it presented more or less the same normal histological picture of the control group. However, small focal areas of degenerated muscle fibers and interstitial cellular infiltration remained. Yet, the myofilaments preserved their normal arrangement and regular appearance of sarcomeres and regular rows of intact mitochondria in between myofibrils.

Similar to our findings, Upaganlawar et al. ${ }^{[28]}$, reported that vit $\mathrm{E}$ could only at a dose of $100 \mathrm{mg} / \mathrm{kg}$ restore the ISO-altered hemodynamic parameters such as serum lactate dehydrogenase, serum aspartate transaminase and serum alanine transaminase levels, in addition to different markers of oxidative stress and lipid peroxidation.

This coincided with Padmanablan and Prince ${ }^{[45]}$ who reported that $\alpha$-tocopherol could ameliorate ISO-induced myocardial toxicity, resulting in preservation of the cardiac mitochondrial membrane and lysosomal enzymes. In many studies, vitamin E showed the ability to protect cells and subcellular structures from oxidative damage through inhibiting the formation of ROS ${ }^{[16,46]}$.

Moreover, they have reported that vitamin E could neutralize lipid peroxidation due to its oxygen scavenging effect. Furthermore, vitamin E was able to stabilize heart phospholipids by preventing the change in fatty acid composition and the peroxidative deterioration ${ }^{[47]}$. Nevertheless, vitamin E not only reduces lipid peroxidation but also preserves glutathione levels in high amounts in these tissues by either encouraging the synthesis of endogenous antioxidants or inhibiting the generation of oxidants such as ROS through supporting the endogenous antioxidant system ${ }^{[29,48]}$.

\section{CONCLUSION}

Pretreatment with a high dose of vitamin E had proven effective against the structural changes of the cardiac muscle induced by isoproterenol. While pretreatment with a low dose of vitamin $\mathrm{E}$ did not protect against the deleterious alterations in the structure of myocardium associated with cardiovascular diseases.

\section{CONFLICT OF INTEREST}

There are no conflicts of interest.

\section{REFERENCES}

1. Aronow, WS. Epidemiology, pathophysiology, prognosis, and treatment of systolic and diastolic heart failure. Cardiol Rev 2006; 14: 108- 124.

2. Rajdurai, M and Prince, PSM. Preventive effect of naringin on cardiac markers, electrocardiographic patterns and lysosomal hydrolases in normal and isoproterenol-induced myocardial infarction in Wistar rats. Toxicology 2007; 230(2- 3): 178 -188.

3. Kloner, RA. New observations regarding postischemia/reperfusion myocardial swelling. J Am Coll Cardiol 2015; 65(4): 324- 326.

4. Stanely Mainzen Prince, P, Dhanasekar, K, Rajakumar, S. Vanillic acid prevents altered ion pumps, ions, inhibits Fas-receptor and caspase mediated apoptosis-signaling pathway and cardiomyocyte death in myocardial infarcted rats. Chem Biol Interact. 2015; 232: 68- 76.

5. Zhu, P, Liu, J, Shi, J, Zhou, Q, Liu, J, Zhang, X, Du, Z, Liu, Q, Guo, Y. Melatonin protects ADSCs from ROS and enhances their therapeutic potency in a rat model of myocardial infarction. J Cell Mol Med 2015; 19(9): 2232- 2243.

6. Sushamakumari, S, Jayadeep, A, Kumar, SH, Menon, VP. Effect of carnitine on malondialdehyde, taurine and glutathione levels in heart of rats subjected to myocardial stress by isoproterenol. Ind J Exp Biol 1989; 27: 134- 137.

7. Panda, VS, Naik, SR. Evaluation of cardioprotective activity of Ginkgo biloba and Ocimum sanctum in rodents. Altern Med Rev 2009; 14: 161-171. 
8. Kannan, MM, Quine, SD. Ellagic acid inhibits cardiac arrhythmias, hypertrophy and hyperlipidaemia during myocardial infarction in rats. Metabolism 2013; 62: 52-61.

9. Zhang, GX, Kimura, S, Nishiyama, A, Shokoji, T, Rahman M, Yao, L, Nagai, Y, Fujisawa, Y, Miyatake A, Abe Y. Cardiac oxidative stress in acute and chronic isoproterenol-infused rats, Cardiovasc Res 2005; 65: 230-238.

10. Jing, L, Wang, Y, Zhao, X, Zhao, B, Han, J, Qin, S, Sun, X. Cardioprotective Effect of Hydrogenrich Saline on Isoproterenol-induced Myocardial Infarction in Rats. Heart Lung Circ 2015, 24(6): 602-610.

11. Pauletti, PM; Castro-Gamboa, I; Siqueira Sliva, DH, Young, MC, Tomazela, DM, Eberlin, MN and Silva Bolzani, V. New antioxidant C-glucosylxanthones from the stems of Arrabidaea samydoides. J Nat Prod 2003; 66: 1384 -1387.

12. Goyal, SN, Sharma, C, Mahajan, UB, Patil, CR, Agrawal, YO, Kumari, S, Arya, DS and Ojha, S. Protective Effects of Cardamom in IsoproterenolInduced Myocardial Infarction in Rats Int J Mol Sci 2015; 16(11): 27457-27469.

13. Ribeiro, DA, Buttros, JB, Oshima, CT, Bergamaschi, RC. Ascorbic acid prevents acute myocardial infarction induced by isoproterenol in rats: role of inducible nitric oxide synthase production. J Mol Hist 2009; 40: 99 -105.

14. Munteanu, A, Zingg, JM, Azzi, A. Antiatherosclerotic effects of vitamin E- myth or reality. J Cell Mol Med 2004; 8: 59- 76.

15. Clark, MW, Burnett, JR, Caroft KD. Vitamin E in human health and disease. Crit Rev Clin Lab Sci 2008; 45: 417- 450.

16. Ayaz, SA, Bhandari, U, Pillai, KK. Influence of D1 $\alpha$-lipoic acid and vitamin $\mathrm{E}$ against doxorubicininduced biochemical and histological changes in the cardiac tissue of rats. Ind J Pharmacol 2005; 37(5): $294-299$.

17. Nandave, M, Mohanty, I, Nag, TC, Ojha, SK, Mittal, R, Kumari, S, Arya, DS. Cardioprotective response to chronic administration of vitamin $\mathrm{E}$ in isoproterenol induced myocardial necrosis: hemodynamic, biochemical and ultrastructural studies Indian Journal of Clinical Biochemistry, 2007,22 (1) $22-28$

18. Upaganlawar, A, Gandhi, H, Balaraman, R,. Isoproterenol Induced Myocardial Infarction: Protective Role of Natural Products. J Pharmacol Toxicol 2011; 6: 1- 17 .
19. Kumar, YS, Arunachalam, G, Senthil, KS, Rajakannu, S, Arumugam, S, Thiruvengadum, D. Synergistic interactions of ferulic acid with ascorbic acid: its cardioprotective role during isoproterenol induced myocardial infarction in rats. Mol Cell Biochem 2006; 283 (1- 2 ):139 -46.

20. Devika, PT and Prince, SM. Epigallocatechingallate (EGCG) prevents mitochondrial damage in isoproterenol-induced cardiac toxicity in albino Wistar rats: a transmission electron microscopic and vitro study. Pharmacol Res 2008; 57: 351 -357.

21. Abdella, EM, Galaly, SR, Mohammed, HM, khadrawy, SM. Protective role of vitamin E against valoproic acid-induced cytogenotoxicity and hepatotoxicity in mice. J. Basic \& applied zoo 2014; (67): 127- 139.

22. Gaertner, DJ, Hallman, TM, Hankenson, FC Batchelder, MA. Anesthesiaand Analgesia for Laboratory rodents In: Fish RE, Danneman PJ, Brown m, Karas AZ editors Anesthesia and Analgesia in Laboratory Animals, $2^{\text {nd }}$ edition. London (UK) Academic Press 2008; pp 239 -297

23. Bancroft, JD and Gamble, M. Theory and practice of histological techniques, sixth edition, Philadelphia: Churchill Livingstone Elsevier 2008; pp 126- 127

24. Bozzola, JJ and Russell, LD. Electron microscopy: principles and techniques for biologists, second edition, Boston, Jones and Bartlett Publishers 1999; pp 100- 124.

25. Padmanabhan, M. and Prince, PSM. Preventive effect of S- allycysteine on lipid peroxides and antioxidants in normal and isoproterenol-induced cardiotoxicity in rats: A histopathological study. Toxicology 2006; 224: $128-37$.

26. Vennila, L, Pugalendi, KV. Protective effect of sesamol against myocardial infarction caused by isoproterenol in Wistar rats. Redox Rep 2010;15: 36-42.

27. Lobo Filho, HG, Ferreira, NL, Sousa, RB, Carvalho, ER, Lobo, PL, Lobo Filho, JG Experimental model of myocardial infarction induced by isoproterenol in rats. Rev Bras Cir Cardiovasc. 2011; 26(3): 469- 476.

28. Upaganlawar, A, Gandhi, Ch, Balaraman, R. Effect of green tea and vitamin E combination in isoproterenol induced myocardial infarction in rats. Plant Foods Hum Nutr 2009; 64(1): 75- 80.

29. Asdaq, SM, Inamdar, MN, Asad, M, Najundan, PK. Interaction of propranolol with a garlic on 
isoproterenol induced myocardial infarction in rats. J Pharmacol Toxicol 2008; 3 (6): 414 -424.

30. Gayathri, V, Ananthi, S, Chandronitha, C, Ramakrishnan, G, Sundaram, RL, Vasanthi, HR. Cardioprotective effect of Nerium Oleander flower against isoproterenol-induced myocardial oxidative stress in experimental rats. J Cardiovasc Pharmacol Ther 2011;16: 96-104.

31. Hassan, MQ, Akhtar, MS, Akhtar, M, Ali, J, Haque, SE, Najmi, AK. Edaravone protects rats against oxidative stress and apoptosis in experimentally induced myocardial infarction: Biochemical and ultrastructural evidence. Redox Rep. 2015; 20(6): $275-281$.

32. Neri, M, Fineschi, V, Di Paolo, M, Pomara, C, Riezzo, I, Turillazzi, E, Cerretani, D. Cardiac oxidative stress and inflammatory cytokines response after myocardial infarction. Curr Vasc Pharmacol. 2015; 13(1): 26 -36.

33. Sabeena Farvin, KH, Anandan, R, Kumar, SH, Shiny, KS, Sankar, TV, Thankappan, TK. Effect of squalene on tissue defense system in isoproterenolinduced myocardial infarction in rats. Pharmacol Res 2004; 50: 231 -236.

34. Zhou, B, Wu, LJ, Li, LH, Tashiro, S, Onodera, S, Uchiumi, F, Ikejima, T. Silibinin protects against isoproterenol-induced rat cardiac myocyte injury through mitochondrial pathway after up-regulation of SIRT1. J Pharmacol Sci 2006; 102: 387- 395.

35. Sathish, V, Ebenezar, KK, Devika,T. Biochemical changes on the cardioprotective effect of nicoradil and amlodipin during experimental myocardial infarction in rats. Pharmacol Res 2003; 48: 565- 570.

36. Ravichandran, LV, Puvanakrishnan, R, Joseph, KT. Alterations in the heart lysosomal stability in isoproterenol-induced myocardial infarction in rats, Biochem. Int. 1990; 22: 387-396.

37. Tawfik, MK, Ghattas, MH, Abo-Elmatty, DM, Abdel-Aziz, NA. Atorvastatin restores the balance between pro-inflammatory and anti-inflammatory mediators in rats with acute myocardial infarction. Eur Rev Med Pharmacol Sci 2010;14: 499-506.

38. Raju, K, Balaraman, R, Hariprasad, Vinoth, KM, Ali, A. Cardioprotective effect of Momordica Cymbalaria Fenzl in rats with isoproterenol- induced myocardial injury. J Clin diagn Res 2008; 2(1): $699-705$.

39. Murugesan, M, Manju, V. Luteolin promotes mitochondrial protection during acute and chronic periods of isoproterenol induced myocardial infarction in rats. Egyp Heart J 2013; 65(4): 319-327.

40. Kumaran, KS, Stanely Mainzen Prince, P. Caffeic acid protects rat heart mitochondria against isoproterenol-induced oxidative damage. Cell stress Chaperones 2010,15 (6): 791-806.

41. Prabhu S, Jainu M, Sabitha KE, Shyamala Devi CS. Effect of mangiferin on mitochondrial energy production in experimentally induced myocardial infarcted rats. Vascul Pharmacol 2006; 44: 519-525.

42. Fewell JE and Zhang C. Modulation of heart glycogen by isoproterenol-induced transient tachycardia in newly born rats. The FASEB Journal 2012; 26 (1): lb622

43. Rahmathulla MSB and Devi KL. Modulation and development of isoproterenol-induced myocardial infarction in male wistar rats. Int.Res. J.Pharm. 2013; 4(5): $26-35$.

44. Farvin, KH, Surendraraj, A, Anandan, R. Protective effect of squalene on endogenous antioxidant vitamins in experimentally induced myocardial infarction in rats. Asian $\mathrm{J}$ Biochem 2009; 4: 133 -139.

45. Padmanablan, M and Prince, SM. S-allylcysteine ameliorates isoproterenol-induced cardiac toxicity in rats by stabilizing cardiac mitochondrial and lysosomal enzymes. Life Sci 2007; 80: 972 -978.

46. Kalender, S, Kalender, Y, Ates, A, Yel, M, Olcay, E, Candan, S. Protective role of antioxidant vitamin $\mathrm{E}$ and catechin on idarubicin-induced cardiotoxicity in rats. Braz J Med Biol Res 2002; 35:1379- 1387 .

47. Zhou, BO, Long-Min, WU, Yang. LI, Zhong-Li, L. Evidance for alpha tocopherol regeneration reaction of green tea polyphenols in SDS micelles. Free Redic Biol Med 2005; 38: 78- 84.

48. Metin, G, Atukeren, P, Gumustas, MK, Belce, A, Kayserilioglu, A. The effect of vitamin E treatment oxidative stress generated in trained rats. Tohoku $\mathrm{J}$ Exp Med 2002; 198: 47 -53. 
الملخص العربى

دور جرعات مختلفة من فيتامين هـ فى الوقاية ضد تلف عضلة القلب المحدث بعقار الأيزوبروتيرينول

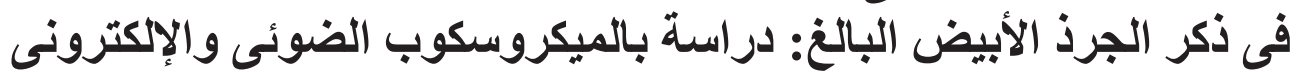

عزة عوض أبو رية1ا ، مروة عوض عبد الحميد إبراهيم1، حبيب أحمد قريشى2

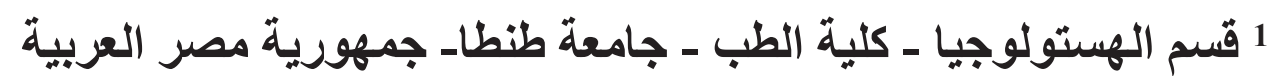

2 قسم العلوم الطبية الحيوية_ كلية الطب-جامعة الملك فيصل ـالمملكة العربية السعودية

المقدمة: تعتبر أمر اض القلب و الثر ايين أحدى الأمر اض السائدة في العالم. وبالتالي فمن المهم إيجاد أدوية طبيعية لها القدرة على حماية خلايا عضلة القلب من التلف الفئ الهدف من العمل: تحديد الدور الوقائي للجر عات المختلفة لفيتامين (ه) ضد تلف تلف عضلة القلب المحدث بعقار الأيزوبروتيرينول .

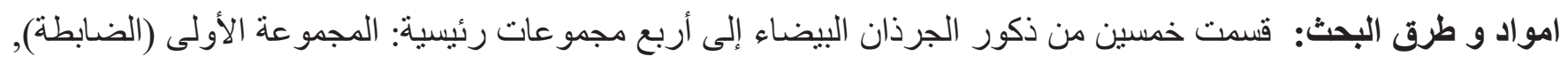

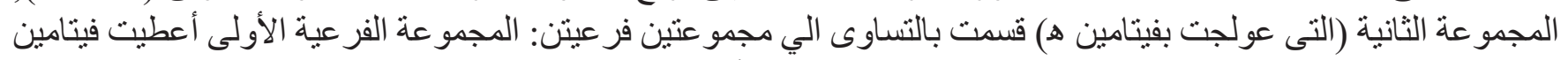

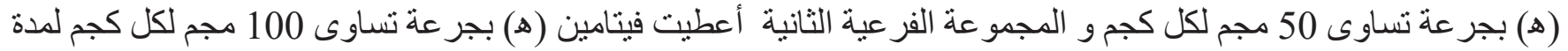

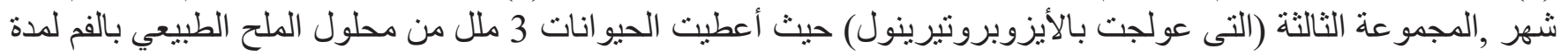

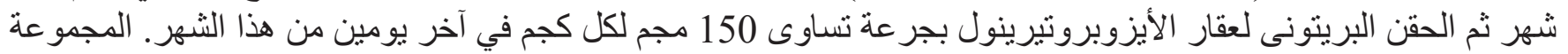

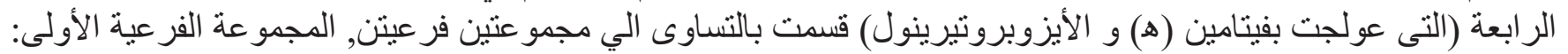

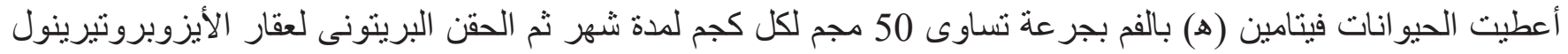

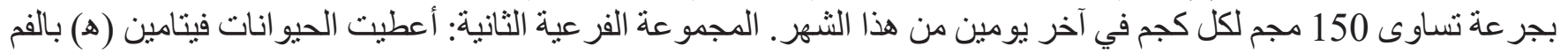

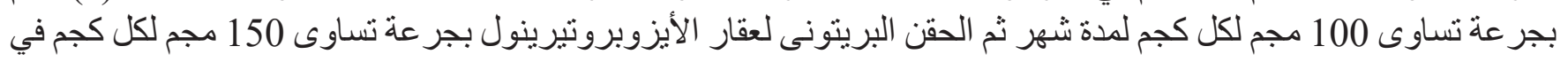

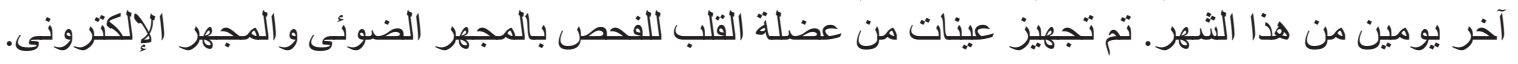

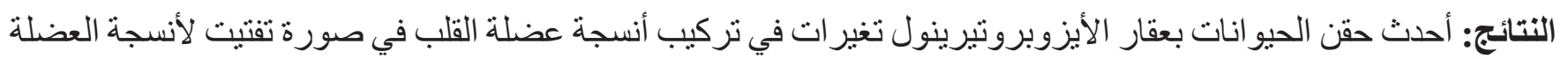

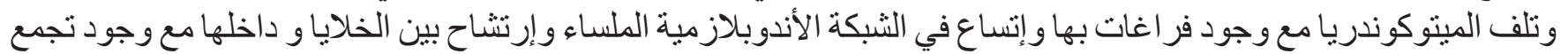

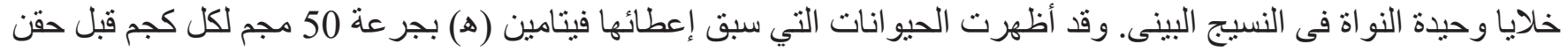

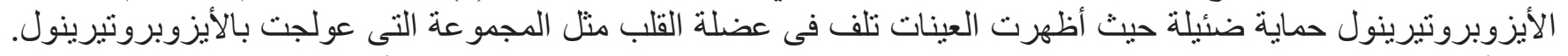

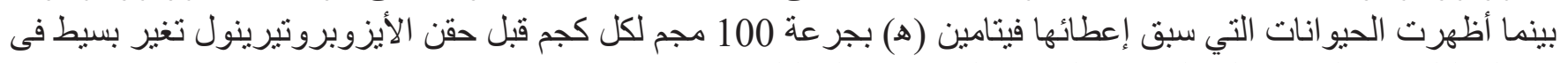

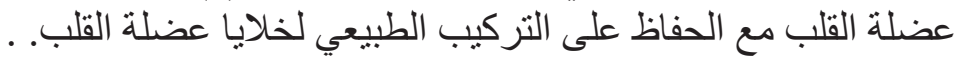
الاستتتاج: إعطاء فيتامين (ه) بجر عة كبيرة (100 مجم لكل كجم) له دور فعال في الحماية من تلف عضلة القلب المحدث بعقار الأيزوبروتيرينول. 